\title{
FLORA DA SERRA DO CIPÓ, MINAS GERAIS: ASTERACEAE - SENECIONEAE ${ }^{1}$
}

\author{
ARISTÔNIO MAGALHÃES TELES* \& JOÃO RENATO STEHMANN** \\ * Universidade Federal de Goiás, Instituto de Ciências Biológicas, Departamento de Biologia Geral, \\ Caixa postal 131, 74001-970 - Goiânia, GO, Brasil. \\ ** Universidade Federal de Minas Gerais, Instituto de Ciências Biológicas, Departamento de Botânica, \\ Caixa postal 486, 31270-901 - Belo Horizonte, MG, Brasil.
}

\begin{abstract}
Flora of the Serra do Cipó, Minas Gerais: Asteraceae - Senecioneae). The study of the tribe Senecioneae (Asteraceae) is part of the project "Flora of the Serra do Cipó, Minas Gerais, Brazil". In that area the tribe is represented by the following genera, with their respective number of species: Emilia (1), Erechtites (1), Hoehneophytum (1), Pentacalia (1), Pseudogynoxys (1) and Senecio (4). Key to the genera and species, descriptions, illustrations, as well as comments on the geographic distribution, habitats, phenology and morphological variability of the species are presented.
\end{abstract}

Key words: Compositae, floristics, taxonomy, Espinhaço Range.

\begin{abstract}
Resumo - (Flora da Serra do Cipó, Minas Gerais: Asteraceae - Senecioneae). O estudo da tribo Senecioneae é parte do projeto "Flora da Serra do Cipó, Minas Gerais, Brasil". Esta tribo está representada na área pelos seguintes gêneros com o respectivo número de espécies: Emilia (1), Erechtites (1), Hoehneophytum (1), Pentacalia (1), Pseudogynoxys (1) and Senecio (4). São apresentadas chaves de gêneros e de espécies, descrições, ilustrações, comentários sobre distribuição geográfica, habitat, fenologia e variabilidade morfológica das espécies tratadas.
\end{abstract}

Palavras-chave: Compositae, florística, taxonomia, Cadeia do Espinhaço.

\section{Tribo Senecioneae Cass.}

Ervas, arbustos, lianas, epífitas ou árvores. Folhas geralmente alternas, caulinares ou rosuladas, sésseis ou pecioladas, inteiras ou variadamente sectadas. Capítulos heterógamos ou homógamos, radiados, disciformes ou discóides, solitários ou dispostos em capitulescências terminais ou laterais, corimbiformes, paniculiformes ou tirsóidesra; pedúnculos bracteolados ou ebracteolados. Invólucro geralmente unisseriado, caliculado ou ecaliculado. Brácteas involucrais livres ou conadas. Receptáculo plano, convexo ou cônico, sólido ou fistuloso. Flores geralmente amarelas, algumas vezes brancas, alaranjadas, rosadas, vermelhas, lilás ou raramente azuis. Flores do raio geralmente pistiladas; corola liguliforme ou tubular-filiforme. Flores do disco perfeitas ou funcionalmente estaminadas, raramente pistiladas; corola tubulosa, 4-5-lobada. Anteras 4-5, ápice apendiculado, base obtusa, sagitada ou caudada; colar reto, uniforme ou basalmente dilatado. Estilete geralmente bífido, ramos com ápice truncado ou convexo, arredondado ou cônico, algumas vezes com apêndice alongado, papiloso ou hirsuto, ou somente com tricomas apicais curtos, ocasionalmente com distinto tufo de tricomas central ou tricomas penicelados ou ainda papilas fusionadas. Cipselas costadas, obovóides, algumas vezes achatadas ou angulosas, glabras ou variavelmente pubescentes. Pápus de poucas a muitas cerdas, 1-multisseriado, persistentes ou caducas, finas a paleáceas, barbeladas a subplumosas, brancas ou estramíneas, vermelhas ou ainda púrpuras.

Senecioneae é a maior tribo em número de espécies entre as Asteraceae, com cerca de 3500 espécies agrupadas em 150 gêneros (Nordestam 2007), sendo que aproximadamente um terço destas ocorre no Novo Mundo (Hind 1993). As espécies de Senecioneae são praticamente cosmopolitas, com exceção dos pólos, mas concentram-se predominante na América do Sul e Central, África do Sul e tropical, além da porção central e oriental da Ásia (Bremer 1994).

$\mathrm{Na}$ Serra do Cipó a tribo Senecioneae está representada por seis gêneros e nove espécies.

Bibliografia básica: Baker (1884), Belcher (1956), Cabrera (1957), Cabrera \& Klein (1975), Robinson \& Cuatrecasas (1977), Jeffrey (1992), Hind (1993), Hind (1999), Nordenstam (2007), Teles (2008), Nordenstam et al. (2009). 
1. Brácteas involucrais e flores 5

3. Hoehneophytum

1'. Brácteas involucrais e flores sempre em número maior que 5.

2. Capítulos disciformes ou discóides.

3. Capítulos disciformes 2. Erechtites

3'. Capítulos discóides.

4. Ervas anuais; invólucro ecaliculado; corola filiforme, rósea 1. Emilia

4'. Ervas a arbustos perenes; invólucro caliculado; corola tubulosa, lilás ou amarela 6. Senecio

2'. Capítulos radiados.

5. Plantas escandentes; ramos do estilete com ápice rombudo a longamente acuminado.

6. Margem foliar inteira. Capítulos com flores do raio amarelas; ramos do estilete com ápice rombudo envolto por uma coroa de tricomas divergentes; cipselas 5-costadas

6'. Margem foliar serrada. Capítulos com flores do raio alaranjadas ou avermelhadas; ramos

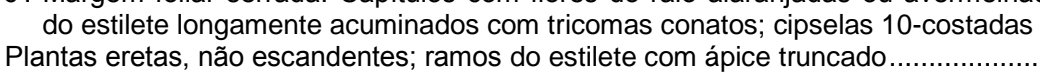
4. Pentacalia 5. Pseudogynoxys

\section{Emilia (Cass.) Cass.}

Ervas eretas, anuais. Caule simples. Folhas ovadas, obovado-lanceoladas ou lanceoladas, ápice agudo a obtuso; base atenuada ou cordada, margem dentada, peninérveas, sésseis ou pecioladas, pecíolos ocasionalmente alados, arrosetadas na base. Capítulos homógamos, discóides, dispostos em capitulescências corimbiformes. Invólucro urceolado, ecaliculado, brácteas involucrais 6-14, conadas. Flores 15-50, perfeitas, corola filiforme, com leve dilatação apical, vermelhas ou róseas. Ramos do estilete com ápice com apêndice triangular ou cônico, linhas estigmáticas contíguas. Anteras com base obtusa. Cipselas cilíndricas, 10-costadas, híspidas entre as costas. Pápus alvacento, persistente.

Gênero com cerca de 100 espécies distribuídas principalmente na África (Nordenstam 2007). No Brasil são encontradas apenas duas espécies que possuem distribuição pantropical: Emilia fosbergii Nicolson e $E$. sonchifolia (L.) DC., (Hind 1993). Na Serra do Cipó está representado apenas por uma espécie.

1.1. Emilia sonchifolia (L.) DC., Contr. Bot. India 24. 1834.

Fig. $1 \mathrm{~A}-\mathrm{C}$

Ervas eretas, anuais, 0,1-0,5 m alt. Caule liso, meduloso, porção basal densamente folhoso, porção apical laxamente folhoso, glabro ou esparsamente pubescente. Folhas basais lirado-lobadas, 10,9-2 x 2-4 $\mathrm{cm}$, ápice obtuso a arredondado, base atenuada em pseudopeciolo, glabras a esparsamente pubescentes em ambas as faces. Folhas apicais lanceoladas a deltóides, gradativamente menores, ápice agudo, base cordada ou sagitada, sésseis, amplexicaules, ambas as faces glabras a esparsamente pubescentes. Capitulescências corimbiformes, laxas. Capítulos com pedúnculos 0,2-1,5 $\mathrm{cm}$ compr., ebracteolados, glabros a esparsamente pubescentes. Invólucro estreitamente cilíndrico, 5-10 x 2$3 \mathrm{~mm}$; brácteas involucrais 6-8, lineares, ápice agudo, glabro ou piloso, dorso glabro; receptáculo plano, alveolado. Flores ca. 40, corola rósea, 8,5 mm compr., 5lobuladas, lóbulos 0,5-0,7 mm compr., apêndice do conectivo oblongo; estilete $7 \mathrm{~mm}$ compr. Cipselas $3 \mathrm{~mm}$ compr., híspidas entre as costas; pápus 7-8 mm.
Material examinado: Minas Gerais, Conceição do Mato Dentro, próximo ao km 170, elev. 800 m, 16.VII.1977, G. Martinelli \& A. Távora 2592 (RB). Santana do Pirapama, Serra do Cipó (Serra da Lapa), Distrito de São José da Cachoeira, estrada Santana do Riacho - Santana do Pirapama, trilha do Rio das Pedras, 20.II.2007, V.C. Souza et al. 32924 (ESA, SPF).

Emilia sonchifolia caracteriza-se pelas flores róseas e pelo invólucro estreitamente cilíndrico com as flores praticamente do mesmo comprimento que o invólucro. Espécie possivelmente originária do Sul da Ásia (Nicolson 1980), porém com distribuição pantropical (Nicolson 1980, Pruski 1997). Nicolson (1980) citou a existência de duas variedades, a típica, pantropical, e $E$. sonchifolia var. javanica (N. Burm.) Mattf., encontrada da Ásia à Oceania. Emilia sonchifolia é pouco frequente na Serra do Cipó, onde foi coletada em campo rupestre. No entanto, esta espécie é encontrada frequentemente como ruderal por toda as regiões Sudeste, Norte e principalmente Nordeste do Brasil. Floresce e frutifica durante todo $o$ ano.

\section{Erechtites Raf.}

Ervas anuais ou perenes. Caule ramificado. Folhas lanceoladas, oblanceoladas, oblongolanceoladas, obovadas, ovadas, oblongo-ovadas ou ovado-lanceoladas, ápice agudo, acuminado, base decurrente, margem subinteira, dentada, lobada, ou pinatilobada a pinatissectas, subpecioladas ou amplexicaules, raramente pecioladas. Capítulos heterógamos, disciformes, dispostos em capitulescências corimbiformes. Invólucro cilíndrico, brácteas involucrais 12-14. Flores marginais 1-multisseriadas, pistiladas, às vezes com rudimento de estames, corola longamente filiforme, amarelas, brancas ou esverdeadas. Flores centrais perfeitas, corola tubulosa. Ramos do estilete com ápice truncado, com apêndice de tricomas papilosos fusionados, envoltos por uma coroa de tricomas divergentes; linhas estigmáticas contíguas. Anteras com base obtusa, auriculadas. Cipselas cilíndricas a obcônicas, 10-costadas, pilosas. Pápus alvacento ou purpúreo, persistente. 


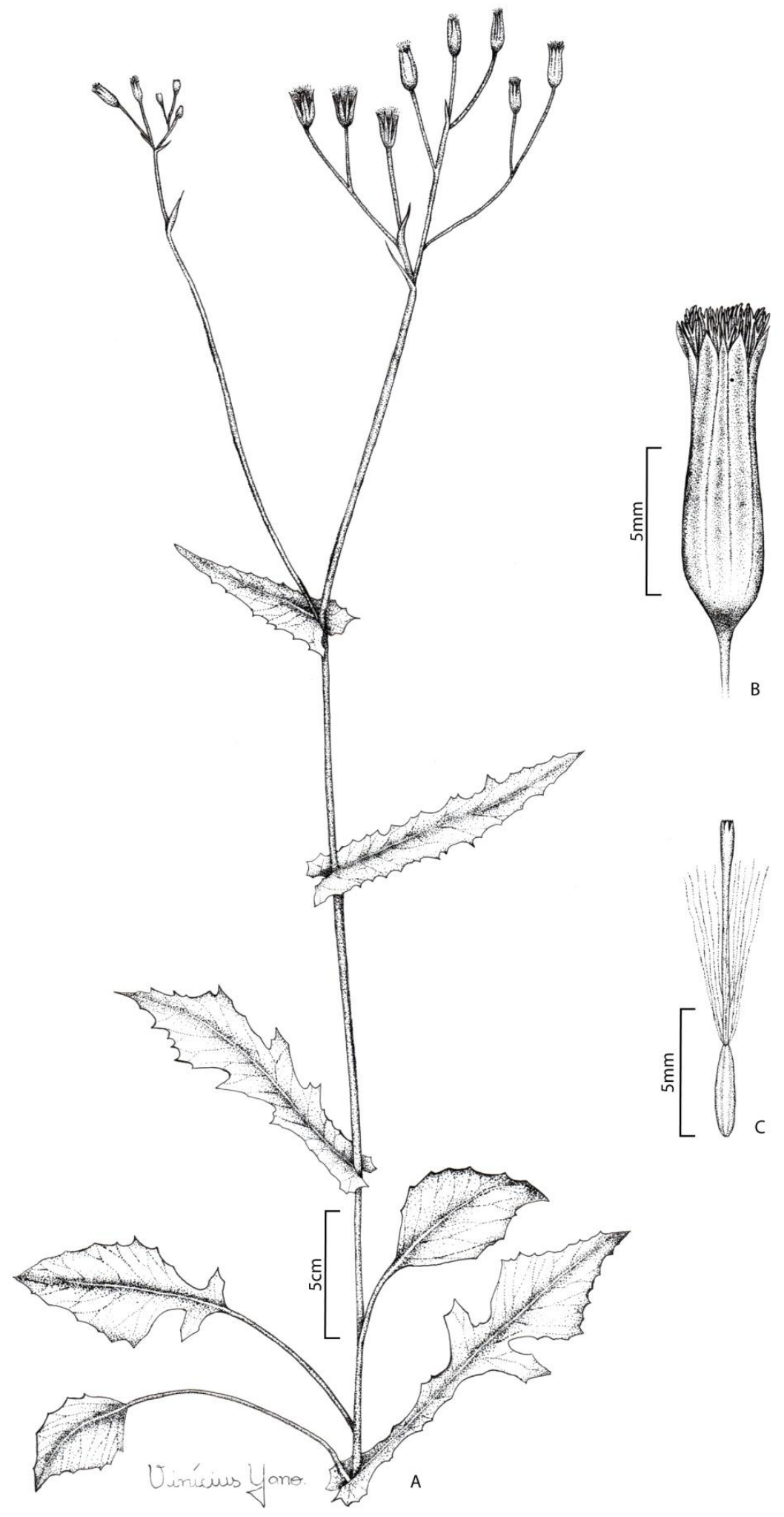

Fig. 1: A-C. Emilia sonchifolia (L.) DC. A. Hábito. B. Capítulo. C. Flor. (Souza et al. 32924).

Bol. Bot. Univ. São Paulo, São Paulo, v. 29, n. 1, p. 57-68, 2011 
Erechtites possui cinco espécies (Belcher 1956; Nordenstam 2007), as quais foram agrupadas por Belcher (1956) em duas seções, E. sect. Hieraciifoliae [E. hieracifolius (L.) Raf. ex DC., E. missionum Malme e E. valerianifolius (Wolf) DC.] e E. sect. Goyazenses [E. goyazensis (Gardner) Cabrera e E. ignobilis Baker]. Para o Brasil é citada a ocorrência das cinco espécies (Hind 1993).

2.1. Erechtites hieracifolius (L.) Raf. ex DC., Prodr. 6: 294. 1838, "hieracifolia".

Fig. 2 D.

Ervas eretas, anuais, 0,2-1,5 m alt. Caule multisulcado, meduloso, densamente folhoso na porção basal, laxamente folhoso na porção apical, esparsamente piloso. Folhas lanceoladas a oblongo-lanceoladas, 2,5-16 $x$ 0,5-3 cm, ápice agudo, base atenuada, margem irregularmente serrada, dentada ou lobada, peninérveas, sésseis, ambas as faces glabras a esparsamente pilosas. Capitulescências laxas a congestas. Capítulos com pedúnculos 2-15 $\mathrm{mm}$ compr., glabros a esparsamente pilosos; bractéolas lanceoladas, 5-8 mm compr., ciliadas. Invólucro 9-12 x 5-8 mm, caliculado; brácteas ca. 14, lineares, 4-4,5 mm compr., ciliadas; brácteas involucrais 12-14, lanceoladas a oblongas, ápice agudo, piloso, margem escariosa, 4-nervadas, dorso glabro; receptáculo plano, alveolado. Flores marginais brancas, esverdeadas ou amareladas, multisseriadas, corola $7 \mathrm{~mm}$ compr., 3-5lobuladas, lóbulos ca. 0,5 mm compr., estilete 7,5 mm compr. Cipselas cilíndricas, 1-3 mm compr., pilosas; pápus $7 \mathrm{~mm}$, branco, persistente. Flores centrais corola branca, esverdeada ou amarelada, 8-8,5 mm compr., 5lobulada, lóbulos $1 \mathrm{~mm}$ compr., apêndice do conectivo oblongo, estilete $8 \mathrm{~mm}$ compr. Cipselas cilíndricas, 1-3 mm compr., pilosas; pápus 7-7,5 mm compr., branco, persistente.

Material examinado: Minas Gerais, Jaboticatubas, Lagoa de D. Ignácia, 6.I.1940, H.L.M. Barreto 10562 (BHCB); Santana do Riacho, Rodovia Belo Horizonte-Conceição do Mato Dentro, entre km 110 e 111, 11.I.1988, R. Mello-Silva et al. CFSC 11018 (SPF); km 132 ao longo da rodovia Belo Horizonte - Conceição do Mato Dentro., 11.I.1981, N.M. Castro \& M.G. Sajo CFSC 6938 (SPF); Ibidem, trilha para a Vellozia gigantea, 4.II.2006, C.A. Garcia \& P.T. Sano 129 (SPF).

Erechtites hieracifolius é uma espécie amplamente distribuida por toda a América tropical, subtropical, África e Ásia (Belcher 1956). Segundo Pruski (1997) a espécie é nativa do Novo Mundo, do Canadá à Argentina, e adventícia na Europa, Índia e China. Belcher (1956) distinguiu três variedades, baseando-se no comprimento das bractéolas do calículo e comprimento das cipselas. Hind (1993) citou para o Brasil a ocorrência apenas de E. hieracifolius (L.) Raf. ex DC. var. cacalioides (Fish. ex Spreng.) Griseb. emend. Belcher, que é encontrada nos estados das regiões Sul, Sudeste, Centro-Oeste, Nordeste (Bahia, Ceará, Pernambuco e Sergipe) e Norte (Acre, Amazonas e Pará).
Na Serra do Cipó a espécie ocorre em campos rupestres com solos arenosos e úmidos, ocorrendo ocasionalmente como ruderal em áreas antropizadas. Coletada com flores e frutos nos meses de janeiro e fevereiro.

\section{Hoehneophytum Cabrera, "Hoehnephytum".}

Arbustos eretos, perenes. Caule simples ou ramificado. Folhas ovadas a elípticas, agudo a obtuso, base aguda, obtusa ou atenuada, margem inteira, subpecioladas a pecioladas, margem. Capítulos homógamos, discóides, dispostos em capitulescências corimbiformes. Invólucro cupuliforme, brácteas involucrais sempre 5. Flores sempre 5, perfeitas, corola tubulosa, amarelas. Ramos do estilete com ápice arredondado, pubérolo apenas dorsalmente; linhas estigmáticas contíguas. Anteras com base obtusa. Cipselas obcônicas, costadas, hirsutas. Pápus alvacento, persistente.

Hoehneophytum é um gênero endêmico do Brasil, possui três espécies distribuidas pela região nordeste (Bahia), centro-oeste (Goiás) e sudeste (Minas Gerais e São Paulo). Na Serra do Cipó ocorre apenas $H$. trixoides (Gardner) Cabrera.

\subsection{Hoehneophytum trixoides (Gardner)}

Cabrera, Brittonia 7: 53. 1950.

Fig. 3 A-E.

Subarbustos a arbustos eretos, perenes, 0,4-2 $\mathrm{m}$ alt. Caule multisulcado, meduloso, densamente folhoso na porção apical, caducifólio na porção basal, glabro. Folhas ovadas a elípticas, 0,8-5,5 x 0,4-3 cm, ápice agudo a obtuso, base aguda, obtusa ou atenuada, margem inteira, triplinérveas a obscuramente peninérveas, ambas as faces glabras, sésseis a pecioladas; pecíolos 1-8 $\mathrm{mm}$ compr., glabros. Capitulescências corimbiformes, congestas. Capítulos com pedúnculos 1-12 mm compr., glabros; bractéolas lanceoladas, 2-5 $\mathrm{mm}$ compr., glabras. Invólucro cupuliforme, $6-10 \times 3-5 \mathrm{~mm}$, ecaliculado; brácteas involucrais 5, oblongas, ápice agudo, piloso, margem escariosa, dorso glabro; receptáculo plano, fimbriado. Flores 5, corola branca a esverdeada, 7-9,5 mm compr., 5-lobulada, lóbulos da corola $3 \mathrm{~mm}$ compr., apêndice do conectivo oblongo; estilete 6,5-11 mm compr. Cipselas obcônicas, 1,5-3,5 mm compr., costadas, hirsutas; pápus 5-8 mm compr., persistente.

Material examinado: Minas Gerais, Jaboticatubas, km 114 ao longo da rodovia Lagoa Santa - Conceição do Mato Dentro - Diamantina, 20.VIII.1972, A.B. Joly \& J. Semir 2865 (UEC); km 127 ao longo da rodovia Lagoa Santa Conceição do Mato Dentro - Diamantina, 19.VII.1972, J. Semir \& M. Sazima 2597 (UEC); Serra do Cipó, nas próximidades da divisa do Parque rumo Conceição do Mato Dentro, 7.XII.1992, H.F. Leitão Filho et al. 27293, 27319 e 27356 (UEC); Serra do Cipó, 5.VIII.1972, G. Hatschbach 29902 (MBM); Serra do Cipó, 6.VIII.1972, G. Hatschbach 29996 (MBM); Santana do Riacho, Distrito de Cardeal Mota, Parque Nacional da Serra do Cipó, propriedade do Prof. 

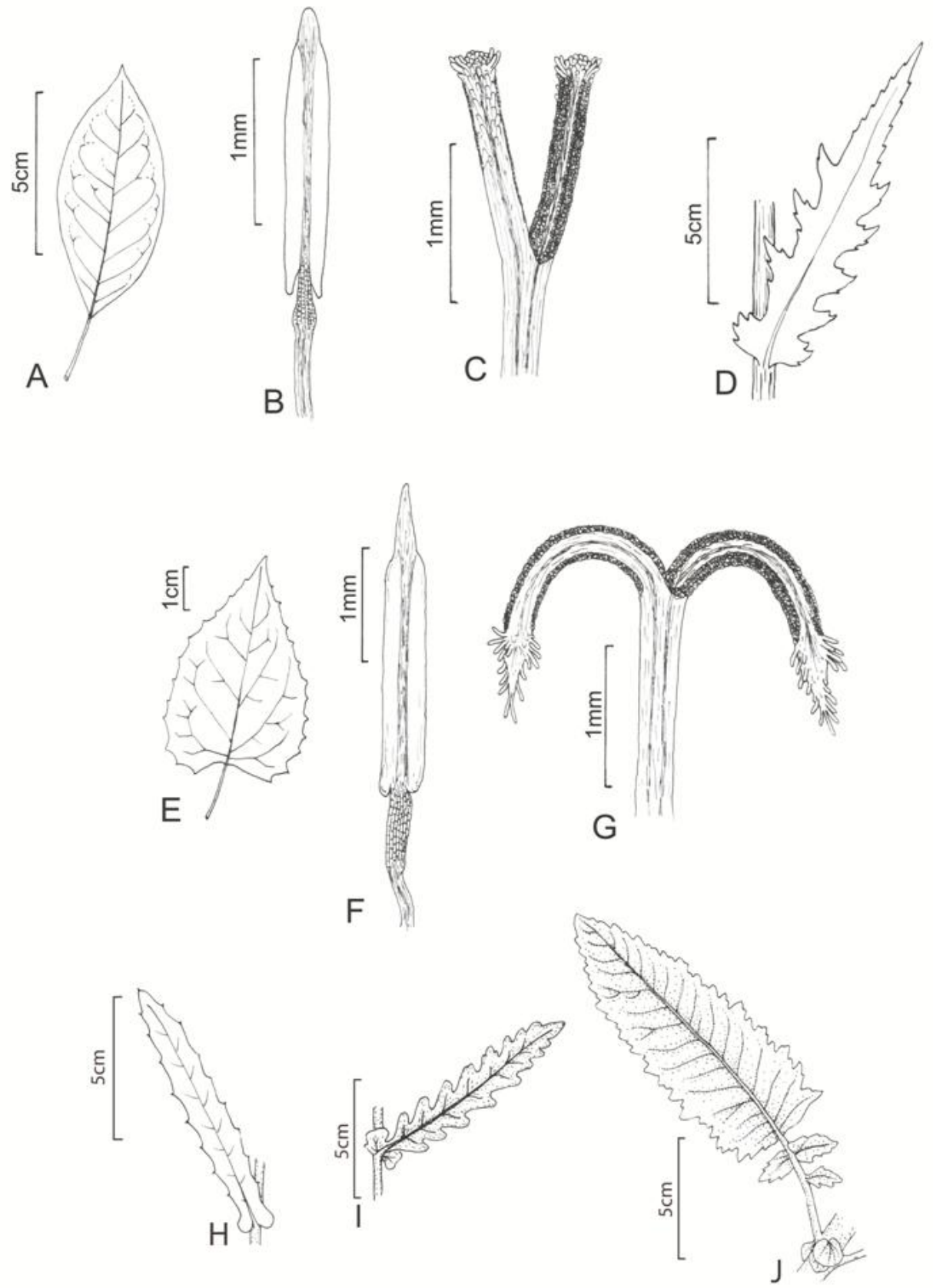

Fig. 2: A-C. Pentacalia desiderabilis (Vell.) Cuatrec. A. Folha. B. Estame. C. Ramos do estilete. D. Erechtites hieracifolius (L.) Raf. ex DC. D. Folha. E-G. Pseudogynoxys cabrerae H.Rob. \& Cuatrec. E. Folha. F. Estame. G. Ramos do estilete. H. Senecio adamantinus Bong. H. Folha. I. Senecio colpodes Bong. I. Folha. J. Senecio macrotis Baker. J. Folha. (A-C. Barreto 9364; D. Barreto 10562; E-G. Roque CFSC 13003; H. Harley et al. 25412; I. Barreto 4200; J. Pereira \& Lucca 856). 
Geraldo Wilson Fernandes (Ecologia / UFMG), 20.X.2006, A.M. Teles 275 (BHCB); entre o km 131 e 132, Palácio, 04.XII.1949, A.P. Duarte 2035 (RB); near $8 \mathrm{~km}$ marker to Fazenda Palácio, 16.XII.1979, G. Martinelli \& G.L. Smith 824 (RB); Serra do Cipó, 12.IX.1986, G.A.R. Melo s.n. (VIC 9747); Parque Nacional da Serra do Cipó, Serra da Bandeirinha, 10.IX.1987, C. Kameyama et al. CFSC 10574 (SPF); Ibidem, 1400-1500 m, 27.VII.1991, A.M. Giulietti et al. CFSC 12503 (SPF); antigo km 115 (atual 110) da Rodovia Belo Horizonte - Conceição do Mato Dentro, 30.VI.1991, J.R. Pirani et al. CFSC 12406 (SPF); Serra da Bandeirinha, 7.XI.1987, R. Simão et al. CFSC 10477 (SPF); estrada atrás da Caixa D'Água da cidade, 28.VII.1991, R. Luque \& N.L. Menezes 17 (SPF); km 116, ao longo da rodovia Belo Horizonte Conceiçao do Mato Dentro, 18.VII.1985, D.C. Zappi CFSC 9328 (SPF).

Hoehneophytum trixoides é uma espécie bastante variável morfologicamente e relativamente comum nos ambientes campestres e rupestres da Serra do Cipó. A espécie pode ser encontrada ainda nos Cerrados de outros estados do Brasil, como Goiás e São Paulo (Hind 1993). Coletada com flores e frutos de julho a dezembro.

\section{Pentacalia Cass.}

Arbustos escandentes, ocasianalmente epífitos, perenes. Caule simples a escassamente ramificado. Folhas elípticas a ovadas, ápice agudo, acuminado, base obtusa a aguda, margem inteira, peninérveas, pecioladas. Capítulos heterógamos, radiados, dispostos em capitulescências tirsiformes a panículascorimbiformes. Invólucro campanulado, brácteas involucrais 8. Flores do raio 5, pistiladas, corola liguliforme, amarelas ou brancas. Flores do disco 16, perfeitas, corola tubulosa. Ramos do estilete com ápice rombudo, envolto por uma coroa de tricomas divergentes; linhas estigmáticas contíguas. Anteras com base sagitada. Cipselas obcônicas, 5-costadas, glabras. Pápus alvacento, persistente.

Pentacalia é um gênero americano com grande concentração de espécies especialmente nos Andes, porém distribuido desde a América do Sul à Central (México) (Nordenstam 2007). Possui cerca de 200 espécies que são caracterizadas principalmente pelas folhas conspicuamente coriáceas e pelo hábito escandente ou epifítico (Nordenstam 2007). No Brasil o gênero está representado por duas espécies: $P$. desiderabilis (Vell.) Curatrec. e P. tropicalis (Cabrera) Jeffrey (Hind 1993). Na Serra do Cipó ocorre apenas a primeira.

4.1. Pentacalia desiderabilis (Vell.) Cuatrec., Phytologia 52: 164. 1982.

Fig. 2 A-C.

Arbustos escandentes, perenes, até $20 \mathrm{~m}$ alt. Caule multisulcado, meduloso, laxamente folhoso por toda a extensão, glabro a glabrescente. Folhas elípticas a ovadas, 2-9 x 0,7-5,5 cm, ápice agudo, acuminado, base obtusa a aguda, margem inteira, peninérveas, ambas as faces glabras; pecíolos 0,4-2,5 cm compr., glabros a glabrescentes. Capitulescências tirsiformes a paniculascorimbiformes, congestas. Capítulos com pedúnculos 2$13 \mathrm{~mm}$ compr., bracteolados, glabros ou laxamente lanuginosos; bractéolas lanceoladas, 2-3 mm compr., glabras ou laxamente lanuginosas. Invólucro campanulado, 5-19 x 4-10 mm, caliculado; brácteas do calículo 3-6, lanceoladas, 1,5-4 mm compr.; brácteas involucrais 8, oblongas, ápice agudo, piloso, margem escariosa, dorso glabro; receptáculo plano a levemente convexo, alveolado. Flores do raio 5, corola amarela, tubo da corola amarela, 3,5-4 mm compr., lígula 4-4,5 $\mathrm{x}$ 1-1,2 mm, 4-nervada, ápice 3-dentado. Flores do disco 16, corola amarela, $5 \mathrm{~mm}$ compr., 5-lobulada, lóbulos da corola $1 \mathrm{~mm}$ compr., apêndice do conectivo oblongo; estilete $6 \mathrm{~mm}$ compr. Cipselas obcônicas, 1,5 mm compr., 5-costadas, glabras; pápus 3-9 mm compr., persistente.

Material examinado: Minas Gerais, Conceição do Mato Dentro, Serra do Cipó, km 153, estrada de Conceição, 19.IX.1937, H.L.M. Barreto 9364 (BHCB); Jaboticatubas, km 142 ao longo da rodovia Lagoa Santa - Conceição do Mato Dentro Diamantina, 22.VIII.1972, A.B. Joly \& J. Semir 3189 (UEC).

Pentacalia desiderabilis é facilmente reconhecível por ser uma das poucas espécies de Senecioneae nativas do Brasil com hábito escandente. As outras únicas espécies ocorrentes no Brasil com este hábito são Dendrophorbium pellucidinerve (Sch.Bip. ex Baker) C. Jeffrey (ocasionalmente escandente), Pseudogynoxys cabrerae H. Rob. \& Cuatrec., $P$. chenopodioides (Kunth) Cabrera e P. lobata Pruski. Pentacalia desiderabilis difere da primeira pelas folhas com margem inteira ( $v s$. margem serrada) e das três espécies de Pseudogynoxys pelas flores do raio amarelas ( $v s$. alaranjadas a avermelhadas).

Pentacalia desiderabilis é um arbusto escandente característico das bordas de matas e capões da zona Atlântica, ocorrendo em altitudes que variam de 400 a 2220 m.s.m. (Cabrera \& Klein 1975). Ocorre em todos os estados das regiões sul e sudeste do Brasil (Hind 1993), além da Bahia (Teles \& Stehmann 2008).

$\mathrm{Na}$ Serra do Cipó $P$. desiderabilis pode ser encontrada em bordas de Capões de Mata. Coletada com flores e frutos de agosto a setembro.

\section{Pseudogynoxys (Greenm.) Cabrera}

Subarbustos a arbustos escandentes, perenes. Caule ramificado. Folhas ovadas, ápice agudo, base decurrente ou cordada, margem inteira, crenada, serrada ou lobada, peninérveas, pecioladas. Capítulos heterógamos, radiados, dispostos solitariamente ou em capitulescências corimbiformes. Invólucro campanulado, caliculado, brácteas involucrais 25-35. Flores do raio 618, pistiladas, corola liguliforme, alaranjadas ou avermelhadas. Flores do disco numerosas, perfeitas, corola tubulosa. Ramos do estilete com ápice longamente acuminado com tricomas fusionados; linhas estigmáticas contíguas. Anteras com base obtusa. Cipselas cilíndricas, 10-costadas, densamente pubescentes. Pápus alvacento, persistente. 


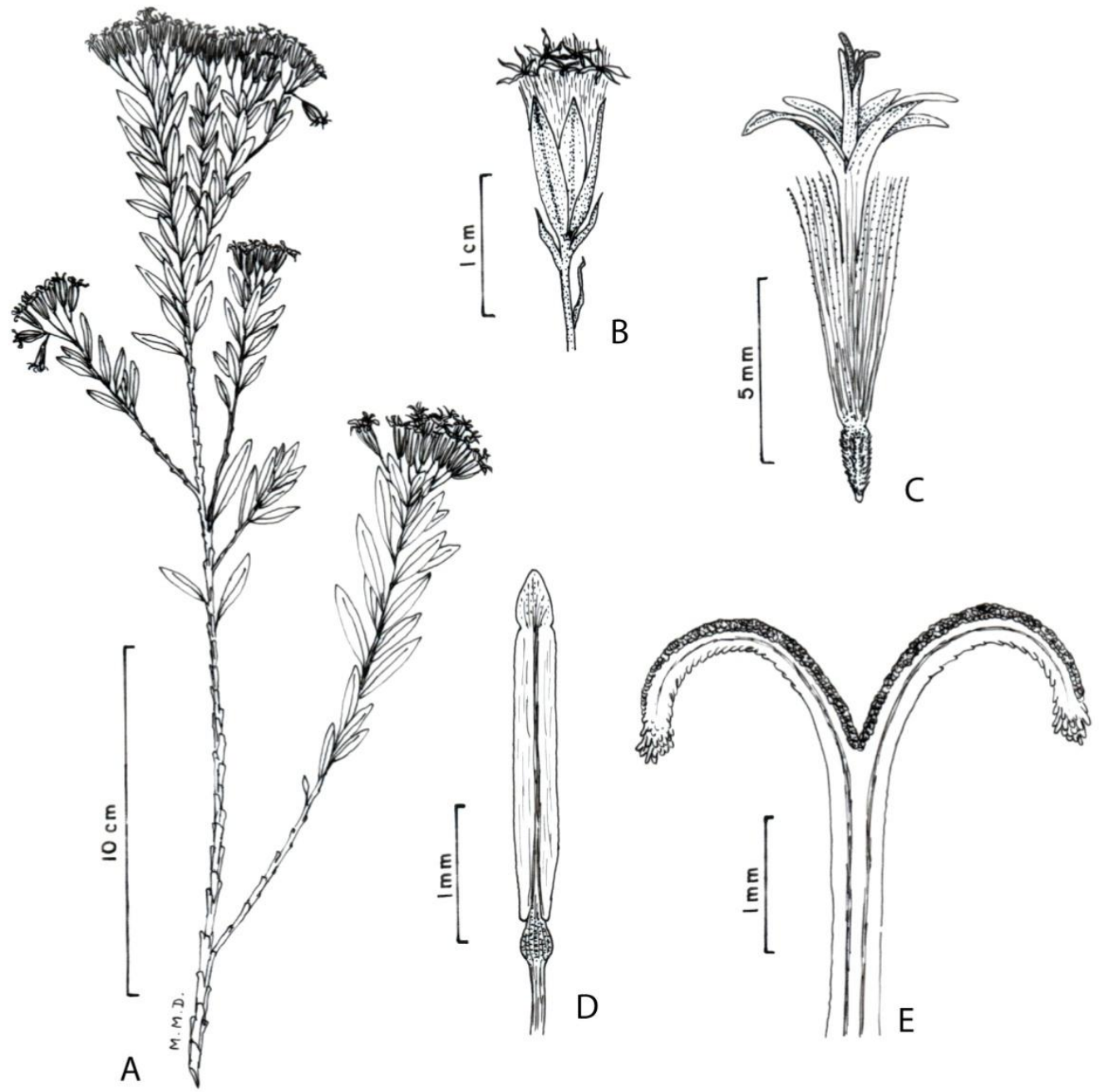

Fig. 3: A-E. Hoehneophytum trixoides (Gardner) Cabrera. A. Hábito. B. Capítulo. C. Flor. D. Estame. E. Ramos do estilete. (Teles 275). 
Pseudogynoxys é um dos gêneros de Senecioneae com ocorrência restrita ao Novo Mundo (Hind 1992). O gênero consta de 13 espécies (Pruski 1996; Nordenstam 2007). Hind (1993) citou apenas a ocorrência de P. cabrerae H.Rob. \& Cuatrec. para o Brasil. No entanto, Pruski (1996) descreveu P. lobata Pruski para a Amazônia brasileira e Matzenbacher (1998) citou a ocorrência de P. chenopodioides (H.B.K.) Cabrera como cultivada como ornamental e às vezes como espontânea no Sul do Brasil, aumentando dessa forma para três o número de espécies ocorrentes no Brasil. Na Serra do Cipó registrou-se a ocorrência apenas de $P$. cabrerae H. Rob. \& Cuatrec.

5.1. Pseudogynoxys cabrerae H.Rob. \& Cuatrec., Phytologia 36: 182. 1977.

Fig. 2 E-G.

Plantas escandentes, perenes. Caule multisulcado, meduloso, pubescente. Folhas ovadas, 3,88,5 x 3-4 cm, ápice agudo, curtamente acuminado, base cordada a subcordada, margem serrada, peninérveas, ambas as faces pubescentes; pecíolos 1-3,5 cm compr., pubescentes. Capitulescências corimbiformes, terminais, laxas. Capítulos com pedúnculos 4,5-10 cm compr., pubescentes; bractéolas lanceoladas, 5-6 mm compr., pubescentes. Invólucro campanulado, 1-20 x 1,5-2,5 cm, caliculado; brácteas do calículo 20-30, lineares a lineareslanceoladas, 5-6 mm compr., pubescentes; brácteas involucrais 25-30, lanceoladas, ápice longo-atenuado, piloso, margem escariosa, dorso pubescente; receptáculo plano a convexo, glabro. Flores do raio 12-18, corola alaranjada ou avermelhada, tubo da corola ca. $8 \mathrm{~mm}$ compr., lígula 13-15 x 3-6 mm, 6-10-nervada, ápice 3dentado. Flores do disco numerosas, corola alaranjada, 11-14 mm compr., 5-lobulada, lóbulos 2-2,5 mm compr., apêndice do conectivo lanceolado; estilete $8 \mathrm{~mm}$ compr. Cipselas cilíndricas, ca. $3 \mathrm{~mm}$ compr., 10-costadas, densamente pubescentes. Pápus 10-12 mm compr., persistente.

Material examinado: Minas Gerais, Jaboticatubas, estrada Belo Horizonte - Conceição do Mato Dentro, próximo ao Hotel Veraneio, 23.XI.1992, N. Roque CFSC 13003 (SPF).

Pseudogynoxys cabrerae foi originalmente descrita para a Argentina, porém também ocorre no Paraguai e no Brasil (Bahia, Mato Grosso do Sul, Minas Gerais, Paraná e São Paulo) (Hind 1992). No Brasil, a espécie é encontrada sob cultivo e de forma subespontânea em bordas de florestas. Na Serra do Cipó, a espécie foi registrada como subespontânea e com flores no mês de novembro.

\section{Senecio L.}

Ervas a arbustos, eretos, prostrados ou decumbentes, anuais ou perenes. Caule simples ou ramificado. Folhas com formas das mais variadas, ápice agudo a obtuso, base variável na forma, margem inteira, crenada, serrada, dentada, lobada ou variavelmente sectada, peninérveas, sésseis ou pecioladas, pecíolos algumas vezes invaginantes, canaliculados ou alados. Capítulos homógamos ou heterógamos, discóides ou radiados, dispostos solitariamente ou em capitulescências diversas. Invólucro campanulado ou cupuliforme, caliculado, brácteas involucrais 7-24. Capítulos discóides com flores perfeitas, corola amarela, lilás ou alvacenta. Capítulos radiados com flores do raio pistiladas, corola liguliforme, normalmente amarela, algumas vezes lilás ou raramente branca. Flores do disco perfeitas, corola amarela, lilás ou alvacenta. Anteras com base obtusa ou ligeiramente aguda. Ramos do estilete com ápice truncado, envolto por uma coroa de tricomas divergentes; linhas estigmáticas contíguas. Cipselas cilíndricas, 5-10costadas, glabras ou pubescentes. Pápus alvacento, caduco ou persistente.

Chave para as espécies

1. Capítulos radiados.

2. Folhas com nervuras inconspícuas na face abaxial (Fig. $2 \mathrm{H}$ ). Brácteas involucrais 7-8; flores do raio 2-3 ...... 1. S. adamantinus

2'. Folhas com nervuras conspicuamente marcadas na face abaxial (Fig. 2 I). Brácteas involucrais 10-12; flores do raio 7-8 1'. Capítulos discóides.

3. Folhas lirado-pinatissectas, densamente albo-tomentosas na face abaxial, pecíolos auriculados

3'. Folhas lanceoladas, pubescentes na face abaxial, sésseis (Fig. 4 A). Flores 40-50, corola lilás 2. S. colpodes 3. S. macrotis 4. S. pohlii

6.1. Senecio adamantinus Bong., Bull. Sci. Acad. Imp. Sci. Saint-Pétersbourg 5: 97. 1838.

Fig. $2 \mathrm{H}$.

Ervas eretas, perenes, $0,5-1 \mathrm{~m}$ alt. Caule multisulcado, fistuloso, porção basal densamente folhoso, porção apical laxamente folhoso, glabro a tomentoso, indumento persistente. Folhas basais obovadas a oblanceoladas, 6-17 x 0,4-4,5 cm, ápice agudo a obtuso, base atenuada, margem inteira, lobada ou dentada, face adaxial esparsamente lanuginosa, face abaxial densamente albo-tomentosa, sésseis. Folhas apicais lanceoladas a oblongo-obovadas, 3-9 × 0,2-1,7 cm, ápice agudo a obtuso, base atenuada, margem inteira, lobada 
ou dentada, face adaxial esparsamente lanuginosas, face abaxial densamente albo-tomentosas, sésseis. Capitulescências corimbiformes, congestas. Capítulos heterógamos, radiados; pedúnculos $3-13 \mathrm{~mm}$ compr., lanuginosos; bractéolas lanceoladas, 3-4 mm compr., glabras. Invólucro cupuliforme, 5-6 x $5 \mathrm{~mm}$; brácteas do calículo ca. 4, lanceoladas, 2,5 mm compr.; brácteas involucrais 7-8, oblongas, ápice agudo, piloso, margem escariosa, dorso glabro; receptáculo plano, alveolado. Flores do raio $2-3$, pistiladas, corola amarela, tubo $2-3$ mm compr., lígula 4-4,5 x 1,5 mm, 4-nervada, ápice 2-3dentado. Flores do disco 6-9, perfeitas, corola amarela, 6 $\mathrm{mm}$ compr., 5-lobulada, lóbulos 1,5 mm compr., apêndice do conectivo oblongo-deltóide; estilete $5 \mathrm{~mm}$ compr. Cipselas obcônicas, 1,5 mm compr., 8-costadas, glabras; pápus 4-5 mm compr., persistente.

Material examinado: Minas Gerais, Congonhas do Norte, Serra Talhada (braço norte da Serra do Cipó), 11,4 km SW da estrada Congonhas do Norte - Gouveia, entrada ramificando a $3,7 \mathrm{~km}$ NE de Congonhas do Norte, estrada pelo alto da serra denominada localmente como "Serra do João Camilo", rumo ao vale do Rio Preto, $18^{\circ} 51^{\prime} 34^{\prime \prime}$, $43^{\circ} 45^{\prime} 27^{\prime \prime} \mathrm{W}$, elev. $1176 \mathrm{~m}, 20 . \mathrm{I} .2004$, J.R. Pirani et al. 5193 (SPF); Jaboticatubas, Serra do Córrego das Congonhas, 19.XI.1942, M. Magalhães 2494 (BHCB); Santana do Riacho, Cardeal Mota, Serra do Cipó, Km 136-138, elev. 1300 m, 6.XII.1949, A.P. Duarte 2098 (RB); Serra do Cipó, km 114 (atual 111), $35 \mathrm{~km}$ ao Sul de Conceição do Mato Dentro, Rod. Belo Horizonte - Conceição do Mato Dentro, 19 $17^{\prime} \mathrm{S}$, 4334'W, 27.X.1988, R.M. Harley et al. 25412 (BHCB, SPF); km 125 da rodovia Belo Horizonte - Conceição do Mato Dentro, pasto próximo à estátua do Velho Juca (margem esquerda), 20.VII.1992, N. Roque \& J.V. Coffani-Nunes CFSC 12967 (SPF).

Senecio adamantinus pertence à seção Adamantina (Cabrera 1957) e tem como espécie mais próxima $S$. colpodes. Baker (1884) e Cabrera (1957) reconheceram duas variedades para essa espécie, a variedade típica e $S$. adamantinus var. integrifolius Baker, que diferencia-se da variedade típica por possuir folhas inteiras ou escassamente dentadas, especialmente as basais (Cabrera 1957). Na Serra do Cipó ocorre a variedade típica.

Senecio adamantinus é uma espécie muito comum nos estados da região sudeste e sul do Brasil, ocorrendo desde Minas Gerais até Santa Catarina, tendo provavelmente o norte de Santa Catarina como o limite austral de distribuição (Cabrera \& Klein 1975). Na Serra do Cipó a espécie ocorre em campos limpos brejosos, campos rupestres e em campos arenosos úmidos. Encontrada com flores em frutos de dezembro a janeiro.

6.2. Senecio colpodes Bong., Bull. Sci. Acad. Imp. Sci. Saint-Pétersbourg 5: 98. 1838.

Fig. 2 I.

Ervas a arbustos eretos, perenes, 0,5-1 m alt. Caule multisulcado, fistuloso, porção basal densamente folhoso, porção apical laxamente folhoso, hirsutoglanduloso. Folhas oblongo-espatuladas, 1,5-12 x 0,3-4 $\mathrm{cm}$, ápice obtuso, base atenuada, margem crenadolobada, 1-nervura por lobo, face abaxial com nervuras conspícuas, face adaxial hirsuto-glandulosas, face abaxial albo-tomentosas, sésseis. Capitulescências panículas-corimbiformes, congestas. Capítulos heterógamos, radiados; pedúnculos $3-27 \mathrm{~mm}$ compr., bracteolados, hirsuto-glandulosos; bractéolas lanceoladas, 4-10 $\mathrm{mm}$ compr., hirsuto-glandulosas. Invólucro cupuliforme, 6-9 x 4-6 mm; brácteas do calículo ca. 6 , lanceoladas, $4 \mathrm{~mm}$ compr.; brácteas involucrais 10-12, lanceoladas, ápice agudo, piloso, margem escariosa, dorso glabro; receptáculo plano, alveolado. Flores do raio $7-8$, pistiladas, corola amarela, tubo $2,5 \mathrm{~mm}$ compr., lígula $8 \times 2,5 \mathrm{~mm}$, 4-nervada, ápice 3-dentado. Flores do disco 18-20, perfeitas, corola amarela, $7 \mathrm{~mm}$ compr., 5lobulada, lóbulo 1,5 mm compr., apêndice do conectivo oblongo; estilete $7 \mathrm{~mm}$ compr. Cipselas cilíndricas, $2 \mathrm{~mm}$ compr., 8-10-costadas, glabras; pápus 5-6 mm compr., persistentes.

Material examinado: Minas Gerais, Conceição do Mato Dentro, estrada de Conceição, 7.VIII.1933, H.L.M. Barreto 4099 (BHCB); Santa Luzia, Serra do Cipó, km 131, 24.VIII.1933, H.L.M. Barreto 4200 (BHCB); Santana do Riacho, Serra do Cipó, km 133, 23.VII.1980, N.L. Menezes et al. CFSC 6377 (SPF); Rodovia Belo Horizonte - Conceição do Mato Dentro, próximo à bifurcação para Morro do Pilar, $19^{\circ} 13^{\prime} 13^{\prime \prime S}, 43^{\circ} 29^{\prime} 57 " W, 5 . V I I .2001$, V.C. Souza et al. 25129 (ESA, SPF).

Senecio colpodes pertence à seção Adamantina Cabrera (Cabrera 1957) e pode ser confundida com algumas formas de $S$. adamantinus (ver comentários sob esta espécie).

Senecio colpodes é uma das espécies típicas dos campos rupestres e campos de altitude de Minas Gerais. Além de ocorrer em Minas Gerais ocorre também no Rio de Janeiro (Hind 1993). Na Serra do Cipó a espécie é encontrada em campos rupestres com solos úmidos próximos a matas de galeria. Floresce e frutifica de julho a agosto. 1884

6.3. Senecio macrotis Baker, FI. Bras. 6(3): 308.

Fig. $2 \mathrm{~J}$.

Ervas robustas ou arbustos eretos, perenes, 1-3 $\mathrm{m}$ alt. Caule multisulcado, fistuloso, densamente folhoso por toda a extensão, densamente albo-tomentoso. Folhas lirado-pinatissectas, lóbulo terminal oblongoovado, $15-26 \times 6-13,5 \mathrm{~cm}$, ápice agudo, base arredondada, margem irregularmente dentada, dentes agudos a obtusos, 1-3 pares de lóbulos opostos, oblongos, agudos a obtusos, $3 \times 1,5 \mathrm{~cm}$, face adaxial laxamente lanosas, face abaxial densamente albotomentosas; pecíolos $3,5-8 \mathrm{~cm}$ compr., auriculados; aurículas reniformes, $1,5-2 \times 2-3 \mathrm{~cm}$. Capitulescências paniculiformes, laxas. Capítulos homógamos, discóides; pedúnculos 10-15 mm compr., densamente tomentosos; bractéolas lanceoladas, 3-3,5 mm compr., glabras. Invólucro campanulado, 8-9 x 5-10 mm; brácteas do calículo ca. 4, linear-lanceoladas, $2-3 \mathrm{~mm}$ compr., 
lanosas; brácteas involucrais 8-13, lanceoladas, ápice agudo, piloso, margem escariosa, dorso glabro; receptáculo plano, alveolado. Flores 10-30, perfeitas, corola amarela, 6,5-7 mm compr., 5-lobulada, lóbulo 1,5-2 $\mathrm{mm}$ compr., apêndice do conectivo oblongo; estilete 7 $\mathrm{mm}$ compr. Cipselas cilíndricas, 2-2,5 mm compr., 10 costadas, papilosas; pápus 7 mm compr., caduco.

Material examinado: Minas Gerais, Serra do Cipó, 14.XI.1990, S.P. Ribeiro S.n. (BHCB 27950); Conceição do Mato Dentro, Capão Redondo, Fazenda Boa Esperança, margem esquerda da rodovia MG 010 Belo Horizonte Conceição do Mato Dentro (km 145 da rodovia), 13.II.1996, N. Roque et al. 152 (SPF); Jaboticatubas, 8.II.1972, J. Semir \& M. Sazima 755 (UEC); ibidem, 6.III.1972, A.B. Joly et al. 1345 (UEC); ibidem, nas proximidades da pensão Chapéu de Sol, 6.III.1972, I. Gemtchujnicov 1395 (UEC); km 142 ao longo da rodovia Lagoa Santa - Conceição do Mato Dentro Diamantina, 22.VIII.1972, A.B. Joly \& J. Semir 3179 (UEC) km 139 ao longo da rodovia Lagoa Santa - Conceição do Mato Dentro - Diamantina, 06.I.1973, J. Semir \& A.M. Joly 3767 (UEC); km 132 ao longo da rodovia Lagoa Santa Conceição do Mato Dentro - Diamantina, 16-24.II.1973, M. Sazima \& J. Semir 3913 (UEC); km 115 ao longo da rodovia Lagoa Santa - Conceição do Mato Dentro - Diamantina, 29.IV.1973, J. Semir et al. 4111 (UEC); ibidem, 1015.XII.1973, J. Semir \& M. Sazima 4764 (UEC); Serra do Cipó, nas proximidades da divisa do Parque, rumo a Conceição do Mato Dentro, 7.XII.1992, H. F. Leitão Filho et al. 27353 (UEC); Santa Luzia, Serra do Cipó, km 140, estrada do Pilar, 11.I.1934, H.L.M. Barreto 4249 (BHCB); ibidem, km 139, estrada do Pilar, 3.II.1934, A. Sampaio 6739 (BHCB); ibidem, 15.IX.1935, H.L.M. Barreto \& A.C. Brade 1097 (RB); ibidem, km 150 da estrada que vai para o Morro do Pilar, 16.IX.1950, A.P. Duarte 3290 (BHCB, RB); Santana do Riacho, Parque Nacional da Serra do Cipó, a $3 \mathrm{~km}$ da portaria Alto Palácio do IBAMA, região das Canelas de Ema Gigantes, 14.VIII, 1992, M. Pereira \& M. Lucca 856 (BHCB); Ibidem, 24.VIII.1992, M. Pereira \& M. Lucca 838 (BHCB); ibidem, elev. ca. 1400 m, 5.I.1993, M. Lucca 18 (BHCB); Serra do Cipó, km 135 (mata ciliar), ao longo da rodovia Belo Horizonte - Conceição do Mato Dentro, 14.XI.1984, M.G. Arrais et al. CFCR 5983 (SPF); Rodovia Belo Horizonte Conceição do Mato Dentro, km 138, próximo à encruzilhada para Morro do Pilar, 11.VII.1987, D.C. Zappi et al. CFSC 10397 (SPF); campo junto à sede do IBAMA do Alto do Palácio, elev. $1370 \mathrm{~m}, 27 . I V .1991$, J.R. Pirani et al. CFSC 12282 (SPF); km 126 da rodovia Belo Horizonte - Conceição do Mato Dentro, Alto do Palácio - Sede do IBAMA, 23.XI.1992, N. Roque CFSC 13009 (SPF); estrada MG-010, cerca de $400 \mathrm{~m}$ antes da bifurcação entre o Morro do Pilar e Conceição do Mato Dentro, primeiro capão W da rodovia, 17.XII.1993, M.T.V.A. Campos \& J.M. Arcanjo CFSC 13582 (SPF); estrada MG-010, cerca de $400 \mathrm{~m}$ antes da bifurcação entre o Morro do Pilar e Conceição do Mato Dentro, segundo capão W da rodovia, 24.V.1994, M.T.V.A. Campos \& E.D.P. Souza CFSC 13736 (SPF); MG 010, Serra do Cipó, Sede do IBAMA do Alto do Palácio, campos rupestres a NE da sede, elev. 1300 m, 8.VI.2002, J.R. Pirani et al. 5073 (SPF).

Senecio macrotis pertence à seção Cacaliastrum (Cabrera 1957) e é caracterizada por possuir folhas lirado-pinatissectas, distintamente discolores e pecíolos com um par de aurículas na base.

Cabrera (1957) e Hind (1993) citaram a espécie como ocorrente unicamente em Minas Gerais, especificamente para a localidade típica, a Serra do Cipó.
No entanto, além da localidade típica, a espécie é conhecida também para outras localidades da Cadeia do Espinhaço, como os municípios de Santo Antônio do Itambé (Pico do Itambé) e São Gonçalo do Rio Preto (Parque Estadual do Rio Preto), em Minas Gerais, e Abaíra (Pico dos Barbados), na Bahia (Teles \& Stehmann 2008).

$\mathrm{Na}$ Serra do Cipó, a espécie forma grandes populações, ocupando extensas áreas de campos rupestres e bordas de capões. Encontrada com flores e frutos durante todo o ano.

\subsection{Senecio pohlii Sch.Bip. ex Baker, FI. Bras.} 6(3): 303. 1884.

Fig. 4 A-E.

Ervas eretas, perenes, 1-1,5 m alt. Caule multisulcado, meduloso, porção basal densamente folhoso, porção apical laxamente folhoso, pubescente. Folhas basais lanceoladas, 3-17,5 x 0,5-3 cm, ápice agudo, base atenuada, margem serrada, ciliada, dentes agudos, face adaxial glabra, face abaxial pubescente, sésseis. Folhas apicais lanceoladas, 0,6-6 6 0,2-1 cm, ápice agudo, base atenuada, margem serrada, dentes agudos, face adaxial glabra, face abaxial pubescente, sésseis. Capitulescências corimbiformes, laxas. Capítulos homógamos, discóides; pedúnculos 2-70 mm compr., pubescentes; bractéolas lanceoladas, 3-4 mm compr., pubescentes. Invólucro campanulado, 6-12 x 4-9 mm; brácteas do calículo 4, lanceoladas, 2,5-5 mm compr.; brácteas involucrais 9-20, oblongas, ápice agudo, piloso, margem escariosa, dorso glabro; receptáculo plano, alveolado. Flores 40-50, perfeitas, corola lilás, $8,5 \mathrm{~mm}$ compr., 5-lobulada, lóbulo 0,5 mm compr., apêndice do conectivo deltóide; estilete $8 \mathrm{~mm}$ compr. Cipselas cilíndricas, 1-1,5 mm compr., 10-costadas, seríceas; pápus 5-7 mm compr., caduco.

Material examinado: Minas Gerais, Conceição do Mato Dentro, Serra do Cipó, km 146 - estrada de Conceição, 12.I.1934, H.L.M. Barreto 8347 (BHCB); lbidem, km 140, estrada de Conceição, 15.IV.1935, H.L.M. Barreto \& A.C. Brade 1084 (BHCB); 7-12 km N de Santana do Riacho, camino a Lapinha, ca. $19^{\circ} 10^{\prime} \mathrm{S}, 43^{\circ} 41^{\prime} \mathrm{W}$, ca. $800 \mathrm{~m}$, 11.II.1991, M.M. Arbo et al. 4857 (SPF); Congonhas do Norte, Serra Talhada (braço norte da Serra do Cipó), 6,8 km SW da estrada Congonhas do Norte - Gouveia, entrada a 3,7 km NW de Congonhas do Norte, estrada pelo alto da serra denominada localmente como "Serra do João Camilo", $18^{\circ} 48^{\prime} 40^{\prime \prime}$ S, $43^{\circ} 45^{\prime} 09^{\prime \prime}$ W, 19.I.2004, J.R. Pirani et al. 5151 (SPF); Jaboticatubas, alto da Serra da Lagoa Dourada, 12.Il.1996, N. Roque et al. 120 (SPF); Santana do Riacho, trilha para a população de Vellozia gigantea, 3.II.2006, M.L.O. Trovó et al. 209 (SPF); estrada da Usina, 9.I.1981, M.C. Henrique et al. CFSC 6892 (SPF); Rodovia Belo Horizonte Conceição do Mato Dentro, km 139, 5.I.1973, C. Muller \& N.L. Menezes 10 (SPF); próximo à Fazenda Boa Vista, 17.II.1982, G.P. Lewis et al. CFSC 7832 (SPF); próximo à estátua do velho Juca, 24.III.1991, J.R. Pirani et al. CFSC 11926 (SPF).

Senecio pohlii pertence à seção Corymbocephalus e à subseção Simplices (Cabrera 


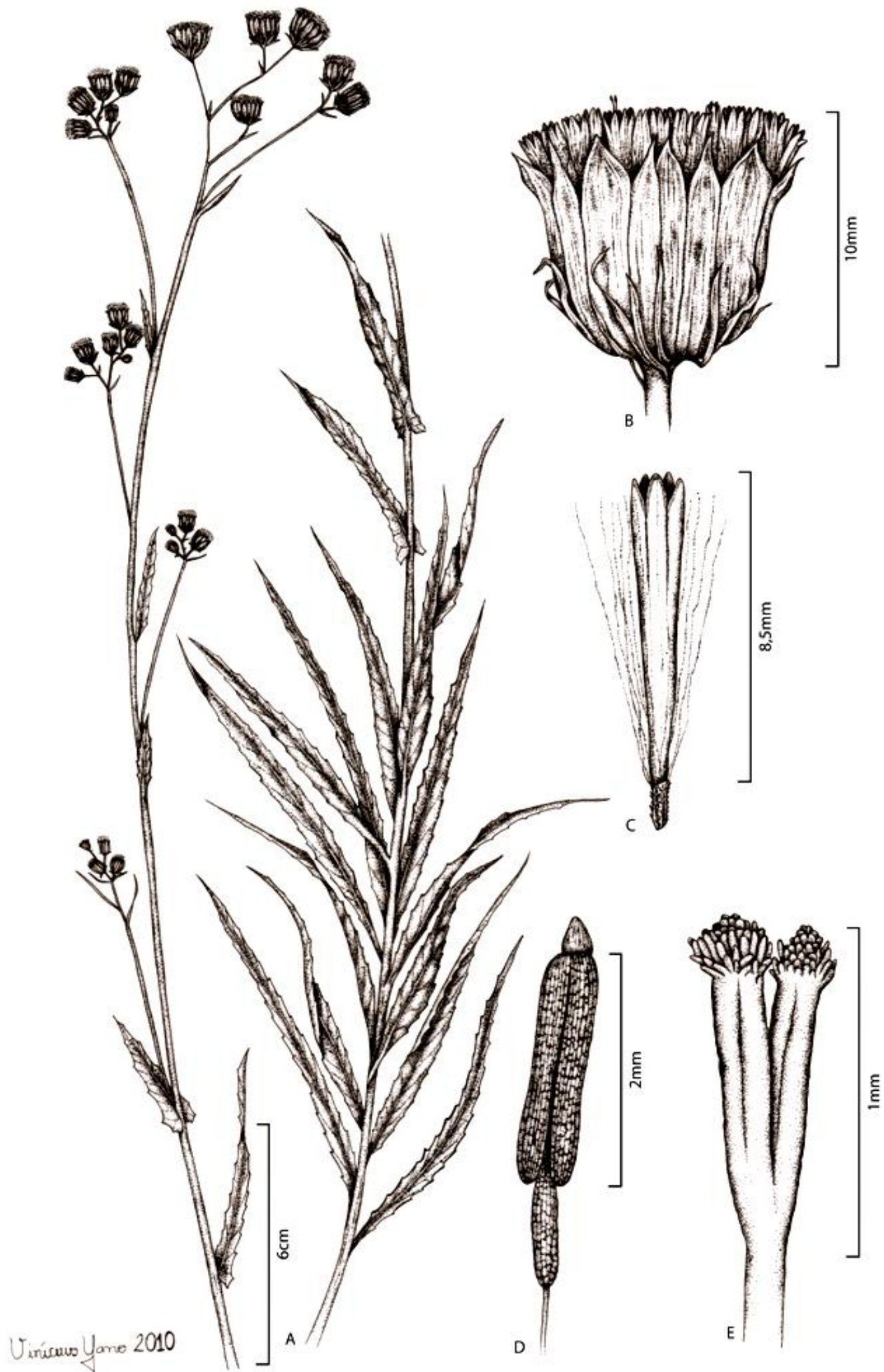

Fig. 4: A-E. Senecio pohlii Sch.Bip. ex Baker. A. Hábito. B. Capítulo. C. Flor. D. Estame. E. Ramos do estilete. (Pirani et al. 5151). 
1957). É uma espécie muito variável morfologicamente, especialmente no tamanho e forma dos capítulos, com invólucro largamente campanulado à estreitamente campanulado, quase cilíndrico.

Espécie encontrada em Goiás, Minas Gerais, Rio de Janeiro e São Paulo (Hind 1993). Em Minas Gerais é a espécie de Senecio com maior distribuição geográfica. Na Serra do Cipó, ocorre em campos rupestres e em campos arenosos com afloramentos rochosos. Floresce e frutifica de janeiro a abril.

\section{Agradecimentos}

Agradecemos a Mírian Morato Duarte e Vinícius Yano Corrêa pela confecção das pranchas. Aos herbários pelo empréstimo de material e facilidades para consulta. À CAPES e ao CNPq, pelas bolsas de doutorado e de Produtividade em Pesquisa, concedidas ao primeiro e segundo autor, respectivamente.

\section{Referências}

BAKER, J.G. 1884. Compositae IV: Helianthoideae Mutisiaceae. In C.F.P. Martius \& A.G. Eichler (eds) Flora brasiliensis. Frid. Fleischer, Münich, Leipzig, vol. 6, pt. 3, p. 135-398, tabs. 82-89.

BELCHER, R.O. 1956. A revision of the genus Erechtites (Compositae), with inquiries into Senecio and Arrhenechthites. Ann. Missouri Bot. Gard. 43: 1-85.

BREMER, K. 1994. Asteraceae: cladistics and classification. Portland, Timber Press. 752 p.

CABRERA, A. L. 1950. Notes on the Brazilian Senecioneae. Brittonia 7: 53-74.

CABRERA, A.L. 1957. El género Senecio (Compositae) en Brasil, Paraguay y Uruguay. Arch. Jard. Bot. Rio de Janeiro 15: 163-264.

CABRERA, A.L. \& KLEIN, R.M. 1975. Compostas - Tribo: Senecioneae. In R. Reitz (ed) Flora llustrada Catarinense. Herbário Barbosa Rodrigues. Itajaí, vol. 2, p. 126-222.

GIULIETTI, A. M., MENEZES, N. L., PIRANI, J. R., MEGURO, M. \& WANDERLEY, M. G. L. 1987. Flora da Serra do Cipó, Minas Gerais: caracterização e lista das espécies. Bol. Bot. Univ. São Paulo 9: 1151.
HIND, D.J.N. 1992. Plant Portraits: 205. Pseudogynoxys cabrerae. Compositae. Kew Mag. 9: 153-156.

HIND, D.J.N. 1993. A checklist of the Brazilian Senecioneae (Compositae). Kew Bull. 48: 279-295.

HIND, D.J.N. 1999. The tribe Senecioneae (Compositae) in Bahia, Brazil, with descriptions of a new section and species in Senecio. Kew Bull. 54: 897-904.

JEFFREY, C. 1992. The tribe Senecioneae (Compositae) in the Mascarene Islands with an annotated world check-list of the genera of the tribe. Notes on Compositae: VI. Kew Bull. 47: 49-109.

MATZENBACHER, N.I. 1998. O complexo "Senecionóide" (Asteraceae - Senecioneae) no Rio Grande do Sul Brasil. Tese de Doutorado. Instituto de Biociências. UFRGS. Porto Alegre. 274 p.

NICOLSON, D.H. 1980. Summary of cytological information on Emilia and the taxonomy of four Pacific taxa of Emilia (Asteraceae: Senecioneae). Syst. Bot. 5: 391-407.

NORDENSTAM, B. 2007. XII. The tribe Senecioneae Cass. 1819. In J. Kadereit \& C. Jeffrey (vol. eds) The families and genera of vascular plants. Flowering plants, Eudicots, Asterales. K. Kubitzki (series ed). Springer. Berlin, vol. 8, p. 208-241.

NORDENSTAM, B., PELSER, P.B., KADEREIT, J.W. \& WATSON, L.E. 2009. Phylogeny of Tribe Senecioneae Cass. In V. Funk, A. Susanna, T. Stuess \& R. Bayer (eds) Systematics, Evolution, and Biogeography of the Compositae. International Association for Plant Taxonomy, Vienna, p. 503-525.

PRUSKI, J.F. 1996. Pseudogynoxys lobata (Compositae: Senecioneae), a new species from Bolivia and Brazil. Syst. Bot. 21: 101-105.

PRUSKI, J.F. 1997. Asteraceae. In P.E. Berry, B.K. Holst \& K. Yatskievych (eds) Flora of the Venezuelan Guayana. Missouri Botanical Garden. St. Louis, vol. 3, p. 177-393.

ROBINSON, H. \& CUATRECASAS, J. 1977. Notes on the genus and species limits of Pseudogynoxys (Greenm.) Cabrera (Senecioneae, Asteraceae). Phytologia 36: 177-192.

TELES, A.M. 2008. Contribuição ao estudo da tribo Astereae no Brasil e Senecioneae (Asteraceae) no Estado de Minas Gerais. Tese de Doutorado. Instituto de Ciências Biológicas. UFMG. Belo Horizonte. $258 \mathrm{p}$.

TELES, A.M. \& STEHMANN, J.R. 2008. Plantae, Magnoliophyta, Asterales, Asteraceae, Senecioneae, Pentacalia desiderabilis and Senecio macrotis: distribution extensions and first records for Bahia, Brazil. Check List 4: 62-64. 